\title{
Fronteiras de Eficiência Estocásticas para as Empresas de Distribuição de Energia Elétrica no Brasil: Uma Análise de Dados de Painel
}

\author{
- Maria Eduarda tannuri-Pianto* - Maria da Conceição Sampaio de Sousa **

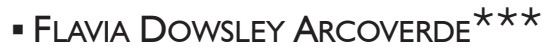

\begin{abstract}
RESUMO
Esse trabalho sugere uma metodologia para análise da eficiência das distribuidoras do setor elétrico brasileiro a partir do estudo econométrico de informações que afetam diretamente a eficiência das empresas distribuidoras, tais como custo operacional, número de funcionários, volume de energia fornecida, e alguns indicadores qualitativos, como o percentual de perdas de energia, a duração média de interrupção de fornecimento por consumidor por ano em horas (DEC) e quantidade média de interrupções de fornecimento por consumidor no ano (FEC). Além desses, são considerados alguns indicadores socioeconômicos como a posse de eletrodomésticos e a densidade demográfica da área de atuação de cada empresa. A análise parte da definição das fronteiras de produção e de custo, sendo seguida pela estimação das funções de fronteira de produção e de custo mediante o uso de fronteiras estocásticas.
\end{abstract}

\section{Palavras-Chave}

eficiência, setor elétrico brasileiro, fronteira estocástica

\begin{abstract}
This paper analyzes the efficiency of the Brazilian electrical sector distributing companies based on an econometrics study of information and data that directly affect distributing companies ' efficiency, such as operational cost, number of employees, volume of energy supplied, and some qualitative indicators, such as the percentage of energy lost, average duration of the supply interruption per year in hours (DEC) and average frequency of the supply interruption per year (FEC). Besides these, some socio-economic indicators are considered, such as appliances ownership and the demographic density of the area each company is located. The analysis starts with the definition of production and cost frontiers, followed by the production and cost frontier functions, applying the Stochastic Frontier Method.
\end{abstract}

KEYWORDS

efficiency, Brazilian electrical sector, stochastic frontier

\author{
JEL CLASSIFICATION \\ L5I, D20, C23
}

\footnotetext{
* Departamento de Economia, Universidade de Brasília. E-mail: tannuri@unb.br.

** Departamento de Economia, Universidade de Brasília. E-mail: mcss@unb.br.

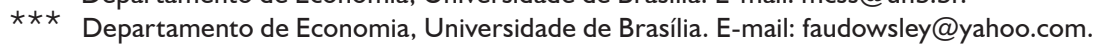

Endereço para contato: Campus Universitário Darcy Ribeiro, Instituto Central de Ciências - Ala Norte. CEP: 709I0-900

- Brasília - DF - Brasil.

(Recebido em novembro de 2005. Aceito para publicação em outubro de 2007).
} 


\section{$1 \quad$ INTRODUÇÃO}

A crise do setor de energia elétrica, que culminou na implementação de um esquema de racionamento, deixou claro que o País enfrenta grandes desafios nessa área posto que o crescimento sustentável depende, crucialmente, da confiabilidade e qualidade do suprimento de eletricidade. Dentre esses desafios destacam-se o atendimento à crescente demanda por serviços de eletricidade no País, inclusive na zona rural e em áreas isoladas, e o aprimoramento de um ambiente institucional, que leve em conta as particularidades desse mercado e garanta a preservação do interesse público em uma esfera em que coexistem diferentes formas de competição. Embora reconhecendo a importância desses fatores, a maioria dos projetos de pesquisa destina-se a estimular melhorias da tecnologia da geração, transmissão e distribuição de eletricidade. Sem questionar a importância desses estudos, vitais para o desenvolvimento do setor, faz-se necessário um melhor conhecimento das condições econômicas que prevalecem nesse mercado.

Nesse contexto, a mensuração da eficiência das empresas do setor energético pode auxiliar no processo regulatório do setor porque, além de nortear as discussões sobre tarifas de energia elétrica, permite fixar padrões para a melhoria da qualidade da prestação de serviços. Para tal, torna-se, pois, necessário definir medidas de eficiência a partir das quais o desempenho dessas empresas possa ser avaliado. Isso pode ser feito com o emprego de fronteiras de eficiência, muito utilizadas para o cômputo dessas medidas. O uso dessas fronteiras justifica-se pelo fato de: (i) a noção de uma fronteira ser consistente com a teoria econômica do comportamento otimizador, (ii) a ênfase no fato de desvios da fronteira terem uma interpretação natural como uma medida de eficiência e (iii) a informação sobre a estrutura da fronteira e sobre a eficiência relativa das unidades econômicas terem muitas aplicações políticas (BAUER, 1990).

Dois paradigmas competem sobre a forma de construir essas fronteiras. Um usa técnicas de programação linear, enquanto o outro emprega métodos econométricos. A principal vantagem da abordagem que usa programação linear, conhecida como 'Data Envelopment Analysis' (DEA), é a não imposição de uma forma funcional explícita para os dados. Todavia, a fronteira calculada pode ser distorcida caso os dados sejam contaminados por erros estatísticos (BAUER, 1990, p.39). A abordagem econométrica compreende a análise de fronteiras determinísticas e estocásticas. Algumas vantagens dessa metodologia são que, ao acomodar ruídos e 'outliers' na base de dados, testes de hipóteses convencionais podem ser realizados. Entretanto, a análise de fronteira estocástica requer que os parâmetros sejam especificados numa forma funcional e que o termo de ineficiência tenha uma forma distribucional especificada, além de não permitir múltiplos produtos (COELLI; RAO; BATTESE, 1998, p. 
187). Uma forma alternativa de usar o método de fronteiras estocásticas consiste na escolha de um sistema de equaçóes (quando aplicável), o que mantém a promessa de estimativas assintoticamente mais eficientes da tecnologia e da eficiência. Todavia, à medida que a forma funcional torna-se mais flexível, ou seja, se afasta daquelas que possuem uma representação de ambas as funções de produção e de custo, a estimação de um sistema de equações torna-se mais difícil (BAUER, 1990).

O objetivo do nosso trabalho é estimar funções de produção e de custo estocásticas para as empresas distribuidoras de energia elétrica brasileiras no período 1993-2001. A partir dessas funções, computaremos os níveis de eficiência dessas firmas a fim de que os resultados encontrados possam fornecer subsídios para as autoridades responsáveis pela regulação do setor energético e demais interessados nesse tema. Ênfase particular será dada à identificação e discussão dos determinantes das ineficiências no setor energético.

Este trabalho organiza-se da seguinte forma. A seção 2 apresenta e discute a metodologia utilizada para o cálculo dos níveis de eficiência das distribuidoras de energia elétrica, no Brasil. A seção 3 apresenta a base de dados do estudo, comenta a escolha das variáveis, e a seção 4 discute os resultados encontrados. Por fim, a seção 5 reúne algumas conclusões do trabalho e sugere extensões.

\section{METODOLOGIA}

\subsection{Funções de Produção Estocásticas}

A função de produção por fronteira estocástica foi independentemente proposta por Aigner, Lovell e Schmidt (1977) e Meeusen e van den Broeck (1977). A especificação original envolve uma função de produção específica para dados "cross-section" com um termo de erro com dois componentes, um para contabilizar os efeitos aleatórios e outro para contabilizar a ineficiência tecnológica. $\mathrm{O}$ modelo de fronteira estocástica é um modelo de regressão estimado por máxima verossimilhança com um distúrbio que é assimétrico e não-normal (GREENE, 2002). Para ilustrar a técnica, suponha que $y=f(\mathbf{x})$ define uma relação de produção entre insumos, $\mathbf{x}$, e um produto, $y$. Então, para qualquer $\mathbf{x}$ dado, o valor observado de $y$ deve ser menor ou igual a $f(\mathbf{x})$. A implicação, em um modelo de regressão empírico, tem uma formulação tal como $y=h(\mathbf{x}, \beta)+u$, sendo $u$ o erro aleatório. Desde que a função de produção teórica seja um ideal - a fronteira de produção eficiente - qualquer distúrbio não-nulo deve ser interpretado como resultante da ineficiência e, 
assim, uma empresa pode ser considerada ineficiente mesmo quando estiver operando acima da fronteira de possibilidades de produção. Além disso, a estimação da função de produção pode ser muito influenciada por um único erro de medida pontual. A fim de solucionar esses problemas, Aigner, Lovell e Schmidt (1977) e Meeusen e van den Broeck (1977) propuseram, independentemente, uma função de produção específica para dados "cross-section", na qual os desvios observados da função de produção poderiam ser obtidos de duas fontes: (i) da ineficiência produtiva, como definida acima e que necessariamente seria negativa; e (ii) dos efeitos idiossincráticos (ou aleatórios), que são específicos à firma e que poderiam entrar no modelo com qualquer um dos sinais. O resultado final foi o que eles chamaram de 'fronteira estocástica’:

$$
\ln y_{i}=\beta_{0}+\beta_{1} \ln x_{1 i}+\beta_{2} \ln x_{2 i}+\cdots+\beta_{k} \ln x_{k i}+v_{i}-u_{i} \quad i=1,2, \ldots, N,
$$

onde os $v_{i}$ 's são distúrbios aleatórios independentes e identicamente distribuídos (i.i.d.) seguindo distribuição normal com média zero e variância $\sigma_{v}^{2}$. Os $v_{i}$ 's capturam as variações ambientais na operação da firma. Os $u_{i}$ 's são distúrbios aleatórios i.i.d. e independentes dos $v_{i}$ 's, normalmente distribuídos com média $\mu_{<}^{\geq} 0$ e variância $\sigma_{u}^{2}$, truncada à esquerda de zero tal que $u_{i} \geq 0$. Os $u_{i}$ 's capturam o desvio da produção atual $\left(y_{i}\right)$ do nível de produção máximo possível $\left(y_{i}=A x_{1 i}^{\beta_{1}} x_{2 i}^{\beta_{2}} \cdots x_{k i}^{\beta_{k}} e^{v_{i}}\right)$; e, assim, fornecem a base para uma medida de eficiência técnica para a firma $i$. Resumindo, todas as firmas na amostra compartilham de uma tecnologia de produção comum ${ }^{1}$. Em seus estudos, Aigner, Lovell e Schmidt (1977) assumem que os $u_{i}$ 's são variáveis aleatórias i.i.d. e independentes dos $v_{i}$ 's com distribuição exponencial ou meio normal. Entretanto, segundo Coelli, Rao e Battese (1998, p. 199): “(...) não há, a priori, uma justificativa para a seleção de qualquer forma distribucional particular para os efeitos da ineficiência técnica, $u_{i}$ ”. Eles argumentam que as distribuições meio normal e exponencial são seleções arbitrárias, desde que ambas essas distribuições possuam moda zero, aumentando a probabilidade de que os efeitos da ineficiência estejam na vizinhança de zero, subestimando-os, portanto. Na prática, é possível que haja pouquíssimas firmas eficientes, mas muitas firmas ineficientes. Em contrapartida, algumas formas distribucionais mais gerais podem ser usadas para medir os efeitos de ineficiência técnica, tais como a distribuição normal truncada (STEVENSON, 1980) e gamma com dois parâmetros (GREENE, 1990).

l O modelo pode ser mais flexível permitindo-se que a tecnologia varie entre as firmas. Isso pode ser alcançado deixando-se que alguns elementos do vetor de parâmetros $\beta$ variem entre as firmas, ou entre subconjuntos da amostra. 
Uma extensão desse modelo pressupõe o uso de dados de painel, em que um número $N$ de firmas sejam observadas ao longo de um número de períodos de tempo $T$. Sua vantagem está no grande número de graus de liberdade na estimação dos parâmetros. Mais interessante, ainda, é que dados de painel permitem a investigação simultânea de uma mudança tecnológica e uma mudança na eficiência técnica ao longo do tempo, dado que a mudança tecnológica é definida por um modelo paramétrico apropriado e os efeitos da ineficiência técnica no modelo de fronteira estocástica são estocásticos e possuem uma distribuição específica. (COELLI; RAO; BATTESE, 1998). Outra extensão desenvolvida por Kumbhakar, Ghosh e McGukin (1991) e Reifschneider e Stevenson (1991) é um modelo de fronteira estocástica em que os efeitos da ineficiência $\left(u_{i}\right)$ são expressos como uma função explícita de um vetor de variáveis específicas da firma e um erro aleatório. Battese e Coelli (1995) propuseram um modelo equivalente à especificação de Kumbhakar, Ghosh e McGukin (1991), com a exceção de que impõem a eficiência alocativa, removem a condição de primeira ordem de maximização de lucro e permitem o uso de um painel.

\subsection{Funções de Custo Estocásticas}

Até o presente momento, a teoria tem sido expressa em termos de uma função de produção, com o $u_{i}$ interpretado como o efeito da ineficiência técnica. Uma representação alternativa da tecnologia de produção é a função custo. A função custo fornece o gasto mínimo necessário para produzir um dado produto, $y$, a partir dos insumos disponíveis, vetor $\boldsymbol{x}$, e de um dado vetor de preços, $\boldsymbol{w}$. Se um produtor é ineficiente, então seus custos de produção devem exceder o mínimo teórico. A interpretação do termo de ineficiência num modelo empírico estimado pela abordagem dual é ligeiramente mais complicada. Diferentemente da produção, onde o termo de erro unilateral é reflexo puro da ineficiência técnica, na função custo quaisquer erros na otimização, técnica ou alocativa, devem aparecer como custos mais altos. De tal forma, um produtor que parece estar operando eficientemente por uma medida da função de produção pode, ainda, parecer ineficiente vis-àd-vis uma função de custo (GREENE, 1997). Coelli, Rao e Battese, (1998, p. 209), citam três razões principais pelas quais se deve considerar a forma dual da tecnologia de produção, as funções custo ou lucro, que são: (i) refletir objetivos comportamentais alternativos; (ii) contabilizar múltiplos produtos; e (iii) prever simultaneamente a eficiência técnica e a alocativa. Para especificar uma função de custo de fronteira estocástica, simplesmente altera-se a especificação do termo de erro de $v_{i}-u_{i}$ da fronteira de produção para $v_{i}+u_{i}$. Isso ocorre porque a função custo representa o custo mínimo, enquanto a função de produção representa o produto máximo. Assim, o $u_{i}$ da função custo define quão acima da fronteira de custo a firma opera. Assumindo-se eficiência 
alocativa, o $u_{i}$ é bem relacionado ao custo da ineficiência técnica. Se essa suposição não é feita, a interpretação do $u_{i}$ numa função de custo torna-se menos clara, com ambas as ineficiências técnica e alocativa possivelmente envolvidas. Então, as medidas de eficiência relativas à fronteira de custos são chamadas de eficiências de custo, e a interpretação exata das mesmas depende da aplicação particular. Schmidt e Lovell (1979) mostram que a estimação de uma fronteira estocástica de custo é similar à estimação da fronteira de produção estocástica. ${ }^{2}$ A abordagem da fronteira de custos é relevante, pois permite a mensuração da ineficiência técnica e alocativa e pode ser facilmente expandida para contabilizar múltiplos produtos (COELLI, 1996). Entretanto, essa abordagem requer disponibilidade de dados sobre os preços dos insumos e variação dos mesmos entre as firmas.

\subsection{Mensuração da Eficiência}

As medidas de eficiência técnica e de custos esperadas de uma firma individual são ambas definidas como:

$$
E F F_{i}=E\left(y_{i}^{*} \mid u_{i}, x_{i}\right) / E\left(y_{i}^{*} \mid u_{i}=0, x_{i}\right),
$$

onde $y_{i}^{*}$ é o produto (ou custo) da $i$-ésima firma, que em nossa aplicação é igual à $\exp \left(y_{i}\right)$ já que a variável dependente está em logaritmos; $u_{i}$ mede a ineficiência (técnica ou de custo) e $x_{i}$ é o vetor das variáveis explicativas. Assim, as medidas de eficiência dependem do valor de $u_{i}$ a ser estimado (predito). Tais medidas são alcançadas pela derivação das expressões para a esperança de $u_{i}$, condicional aos valores observados de $\left(v_{i}-u_{i}\right)$. A expressão relevante para a eficiência técnica da firma $i$ é:

$$
T E_{i}=\frac{y_{i}}{\exp \left(x_{i} \beta\right)}=\frac{\exp \left(x_{i} \beta-u_{i}\right)}{\exp \left(x_{i} \beta\right)}=\exp \left(-u_{i}\right)
$$

Como citado anteriormente, no caso da fronteira de produção, $E F F_{i}$ assumirá valores entre 0 e 1 , enquanto assumirá valores entre 1 e infinito no caso da função custo. Assim, quanto mais próximo de 1 estiver o índice de eficiência estimado, mais eficiente a firma será em ambas as situações: na função custo e na função de produção.

2 Para uma análise mais detalhada, consultar a obra referida. 


\section{DADOS}

A maioria das informações utilizadas para estimar as fronteiras de produção e de custo para 22 (vinte e duas) empresas distribuidoras de energia elétrica brasileiras, no período 1993-2001, provém dos Cadernos de Infraestrutura do Banco de Desenvolvimento Econômico (BNDES). Utilizamos dados que afetam diretamente a eficiência das empresas distribuidoras, tais como custo operacional, número de funcionários, volume de energia fornecida; e também alguns indicadores da qualidade dos serviços oferecidos pelas concessionárias, tais como o percentual de perdas de energia, a duração média de interrupção de fornecimento por consumidor por ano em horas (DEC) e número médio de interrupções de fornecimento por consumidor no ano (FEC). ${ }^{3} \mathrm{O}$ percentual de perdas foi utilizado como uma proxy para o volume de energia comprada, haja vista que essa informação não se encontra disponível. Por fim, o custo da energia comprada foi utilizado como uma proxy para o preço dos contratos de compra das distribuidoras. ${ }^{4}$ Dentre os indicadores de potencial de mercado utilizamos uma medida de posse de eletrodomésticos e a renda mensal da área de atuação de cada empresa. A primeira foi construída a partir dos dados das PNAD's ${ }^{5}$, utilizando-se como ponderação o consumo médio mensal em kWh de energia de cada eletrodoméstico analisado a partir dos dados fornecidos no site do Procel. ${ }^{6}$ A renda mensal da área de atuação de cada empresa foi calculada com base nas informações do censo de 2000 do IBGE e das PNAD's.

Também utilizamos na análise fatores exógenos que não estão sob o controle das empresas, tais como densidade demográfica, a localização regional das empresas. Incluímos dummies para as diferentes regiões do País: Nordeste, Sul, Sudeste e Centro-Oeste. ${ }^{8}$ Criamos também uma variável dummy para a privatização, a fim de capturar o efeito que a privatização teve sobre a ineficiência de cada firma. ${ }^{9}$ Além

3 Esses dados estão disponíveis nos Cadernos de Infraestrutura do BNDES.

4 Esses valores estão disponíveis nos Cadernos de Infraestrutura do BNDES para os anos de 1998 a 2001. Para os demais anos (1993 a 1997), calculou-se a razão entre o custo da energia comprada e o custo operacional apurado (em R $\$$ por $\mathrm{mWh}$ ) para o ano de 1998, e multiplicou-se essa razão pelo custo operacional apurado (em R\$ por $\mathrm{mWh}$ ) em cada ano.

5 Devido à inexistência da PNAD relativa ao ano de 1994, foi realizada uma interpolação nos dados dos demais anos para que esses dados pudessem ser imputados.

6 Os eletrodomésticos utilizados para construir essa variável foram televisor, rádio, geladeira, freezer, fogão e máquina de lavar. Observe que chuveiro elétrico e ar condicionado não estão incluídos no rol de eletrodomésticos devido à ausência de dados nas PNAD's sobre a existência dos mesmos nas residências. A fórmula do cálculo dessa variável é a seguinte: Posse de Eletrodomésticos $=\Sigma$ [(percentual de domicílios que possuem o eletrodoméstico) x (média de consumo mensal do eletrodoméstico em $\mathrm{kWh})]$.

7 Devido à inexistência da PNAD relativa ao ano de 1994, foi realizada uma interpolação nos dados dos demais anos para que esses dados pudessem ser imputados.

8 Como nenhuma das empresas distribuidoras em nossa amostra é da região Norte, essa dummy não é incluída em nossos modelos empíricos.

9 Devido ao fato de os dados em análise serem anuais; as empresas privatizadas entre 1 de janeiro e 30 de junho de um determinado ano são consideradas como privatizadas naquele mesmo ano, enquanto 
dessas, utilizamos uma variável dummy para indicar se a empresa é distribuidora e transmissora (mista) e uma variável para a taxa de participação no mercado calculada como a razão entre o volume de energia (em Kwh) distribuído pela empresa sobre o volume de energia total distribuído (share).

Duas outras variáveis acrescentadas à análise foram o capital e o salário médio. $\mathrm{O}$ capital foi construído a partir do produto entre a receita operacional bruta anual ${ }^{10}$ e a razão do ativo total pela receita líquida em 2001. ${ }^{11} \mathrm{O}$ ideal seria dividir o ativo total de cada ano pela respectiva receita operacional bruta, mas, devido à ausência de informações, isso não foi possível. Cabe ressaltar que isso pode conduzir à superestimação do capital. Já o salário médio foi calculado como o produto entre o custo de pessoal e a razão do volume de energia suprida pelo número de funcionários. ${ }^{12} \mathrm{~A}$ Tabela 1 apresenta as estatísticas descritivas para as principais variáveis utilizadas.

O software utilizado nas estimaçóes dos modelos e dos níveis de eficiência de cada firma foi FRONTIER Versão 4.1, desenvolvido por Coelli e disponível na página do 'Centre for Efficiency and Productivity Analysis'. Esse software utiliza a parametrização sugerida por Battese e Corra (1977) e Battese e Coelli (1995), na qual $\sigma_{v}^{2}$ e $\sigma_{u}^{2}$ são substituídos, respectivamente, por $\sigma^{2}=\sigma_{v}^{2}+\sigma_{u}^{2}$ e $\gamma=\sigma_{u}^{2} /\left(\sigma_{v}^{2}+\sigma_{u}^{2}\right)$, através do cálculo das estimativas de máxima verossimilhança. Dessa forma, o parâmetro $\gamma$ deve ficar entre 0 e 1 e este deve ser o valor inicial a ser utilizado num processo de maximização iterativo tal como o algoritmo de Davidson-Fletcher-Powell. ${ }^{13} \mathrm{O}$ processo de estimação é implementado em um estágio pelo método de máxima verossimilhança e permite considerar dois vetores de variáveis explicativas: o primeiro, vetor $x$, afetando o nível de produção (custo) de fronteira e o segundo, vetor $z$, afetando as ineficiências técnicas. Os vetores $x$ e $z$ podem se sobrepor, já que a posição da fronteira pode depender de fatores outros que não tipicamente insumos, e os insumos podem estar entre os fatores que também afetam as ineficiências técnicas. ${ }^{14}$ As variáveis estão na forma logarítmica e são normalizadas para terem média zero, isto é, as variáveis em nível são divididas por suas médias geométricas sobre $i$ e $t$.

aquelas que foram privatizadas entre 1 de julho e 31 de dezembro, por sua vez, são consideradas como privatizadas no ano subsequente.

10 Idem nota de rodapé 3.

11 Dados disponíveis na página da Internet PIB.

12 Idem nota de rodapé 3.

13 A função de verossimilhança desse modelo encontra-se no apêndice de Battese e Coelli (1992).

14 Wang e Schmidt (2002) realizam um amplo estudo de Monte Carlo, com o qual mensuram o viés envolvido nas estimações em dois estágios, tanto nos parâmetros tecnológicos estimados quanto nos níveis de eficiência e na relação destes com as variáveis explicativas no vetor z. 
TABELA 1 - ESTATÍSTICAS DESCRITIVAS

\begin{tabular}{|c|c|c|c|c|c|c|}
\hline Variáveis & Dimensão & Média & Mediana & $\begin{array}{l}\text { Desvio } \\
\text { Padrão }\end{array}$ & Mínimo & Máximo \\
\hline $\begin{array}{l}\text { Custo Operacional } \\
\text { Total }\end{array}$ & $\mathrm{R} \$ / 1000$ de 2001 & 1095688 & 683665 & 1176673 & 52500 & 7623234 \\
\hline $\begin{array}{l}\text { Volume de } \\
\text { Energia Suprida }\end{array}$ & Mwh & 11035706 & 6244677 & 11811169 & 559383 & 58183210 \\
\hline Salário Médio & R\$ de 2001/funcionários & 42902 & 40924 & 20561 & 12538 & 225496 \\
\hline $\begin{array}{l}\text { Custo da Energia } \\
\text { Comprada }\end{array}$ & $\mathrm{R} \$$ de $2001 / \mathrm{Mwh}$ & 53.42 & 52.19 & 17.92 & 8.7 & 117.93 \\
\hline $\begin{array}{l}\text { Custo dos Outros } \\
\text { Insumos }\end{array}$ & $\mathrm{R} \$$ de 2001 & 35.00 & 31.57 & 14.18 & 14.40 & 80.91 \\
\hline Funcionários & Número de funcionários & 4471 & 2829 & 4402 & 399 & 23463 \\
\hline Capital & $\mathrm{R} \$ / 1000$ de 2001 & 3046047 & 1737106 & 3131397 & 41253 & 14871847 \\
\hline Perdas & $\%$ & 12.45 & 11.80 & 4.89 & 4.60 & 29.40 \\
\hline $\begin{array}{l}\text { Densidade de } \\
\text { Consumidores }\end{array}$ & Consumidores/km2 & 90.75 & 15.03 & 260.57 & 0.43 & 1386.02 \\
\hline $\begin{array}{l}\text { Posse de } \\
\text { Eletrodomésticos }\end{array}$ & $\begin{array}{l}\text { Medida do volume médio } \\
\text { consumido por residência }\end{array}$ & 78.01 & 80.54 & 20.73 & 29.43 & 119.71 \\
\hline $\begin{array}{l}\text { Participação no } \\
\text { Mercado (share) }\end{array}$ & $\begin{array}{l}\text { Volume Mwh empresa/ } \\
\text { Volume Mwh total }\end{array}$ & 0.051 & 0.029 & 0.055 & 0.003 & 0.269 \\
\hline DEC & $\begin{array}{l}\text { Média de interrupção por } \\
\text { consumidor em horas }\end{array}$ & 21.51 & 18.59 & 13.24 & 5.38 & 107.48 \\
\hline FEC & $\begin{array}{l}\text { Quantidade média de } \\
\text { interrupções por consumidor }\end{array}$ & 20.85 & 16.37 & 19.11 & 5.21 & 147.96 \\
\hline
\end{tabular}

O modelo de fronteira estocástica de Battese e Coelli (1995) permite que os efeitos das ineficiências sejam definidos como funções explícitas de fatores específicos das firmas no contexto de dados em painel. As distribuições dos efeitos das ineficiências técnicas não são iguais, mas sim funções de variáveis observáveis. Battese e Coelli (1995) assumem que os efeitos das ineficiências técnicas são independentes, mas não identicamente distribuídos e, consequentemente, as ineficiências mudam no tempo de forma particular para cada firma. Por fim, seguindo a tradição da literatura referente à estimação de fronteiras estocásticas, os níveis de eficiência técnica, estimados em nosso trabalho, foram obtidos levando-se em consideração a orientação pelo produto. ${ }^{15}$

15 Recentemente, Kumbhakar e Tsionos (2006) estimaram uma fronteira de produção estocástica, utilizando uma medida insumo orientada. Esse resultado foi estendido para ser aplicado em funções de custos e de lucros. 
Nesta seção apresentaremos os resultados obtidos com a estimação das funções de produção e de custo, incluindo-se aí os índices de eficiência técnicas, computados a partir dessas funções.

\subsection{Fronteiras de Produção Estocásticas}

O modelo de fronteira estocástica de produção estimado tem a seguinte especificação:

$$
\begin{aligned}
\ln Q_{i t}= & \beta_{0}+\beta_{L} \ln K_{i t}+\beta_{K} \ln L_{i t}+\beta_{P} \ln P_{i t}+\beta_{L L}\left(\ln K_{i t}\right)^{2}+\beta_{K K}\left(\ln L_{i t}\right)^{2}+\beta_{P P}\left(\ln P_{i t}\right)^{2}+ \\
& 2\left[\beta_{K L} \ln \left(K_{i t}\right) \ln \left(L_{i t}\right)+\beta_{K P} \ln \left(K_{i t}\right) \ln \left(P_{i t}\right)+\beta_{L P} \ln \left(L_{i t}\right) \ln \left(P_{i t}\right)\right]+\beta_{K t} \ln \left(K_{i t}\right) . t+ \\
& \beta_{L t} \ln \left(L_{i t}\right) \cdot t+\beta_{P t} \ln \left(P_{i t}\right) . t+\beta_{t} t+\beta_{t t} t^{2}+\alpha_{1} \ln \left(\text { eletro }_{i t}\right)+\alpha_{2} \ln \left(\text { denscon }_{i t}\right)+v_{i t}-u_{i t}
\end{aligned}
$$

$\mathrm{e}$

$\mu_{i t}=\delta_{0}+\delta_{1}$ mista $_{i t}+\delta_{2}$ share $_{i t}+\delta_{3}$ privat $_{i t}+\delta_{4} \operatorname{dec}_{i t}+\delta_{5}$ fec $_{i t}+\delta_{6} N E_{i t}+\delta_{7} S U L_{i t}+\delta_{8} C O_{i t}$

onde $i$ indica a observação da $i$-ésima firma na amostra; $t$ indica o $t$-ésimo período; $Q_{i t}$ é o volume de energia suprido (Mwh); $K_{i t}$ é o capital, $L_{i t}$ é o número de funcionários; $P_{i t}$ é o percentual de perdas; eletro $_{i t}$ é a posse de eletrodomésticos; denscon $_{i t}$ é a densidade de consumidores; e os $v_{i t}$ são assumidos variáveis i.i.d. com distribuição $N\left(0, \sigma_{v}^{2}\right)$ independentes dos $u_{i t}$ 's. Os $u_{i t}$ 's são as ineficiências técnicas não-negativas, distribuídas independentemente, tal que $u_{i t}$ é obtido pelo truncamento em zero da distribuição $N\left(\mu_{i t}, \sigma_{u}^{2}\right)$, onde a média é definida como uma função explícita de um vetor de variáveis específicas da firma, tal como especificado, onde as variáveis foram definidas na seção 3 .

Os resultados obtidos são apresentados nas Tabelas 2 a 4 . Estimamos fronteiras de produção Cobb-Douglas e Translog para as empresas analisadas. Porém, conforme explicitado na Tabela 3, os testes LR refutam a especificação Cobb-Douglas, que requer que os coeficientes cruzados sejam nulos $\left(\beta_{i j}=0\right)$. Por essa razão, apresentaremos aqui somente os resultados para a função Translog. Duas formas distintas dessa especificação foram testadas: na primeira, impusemos a existência de retornos constantes de escala (RCE); na segunda, essa restrição foi eliminada. Embora o teste de Wald rejeite a hipótese de que a tecnologia apresenta RCE (Tabela 3), mantivemos essa especificação porque ela nos permite computar o índice de Malmquist, que 
mensura a variação total na produtividade dos fatores, sendo, pois, relevante para o nosso trabalho. Esse índice só é corretamente definido em presença de retornos constantes de escala (COELLI et al., 1998).

Em ambos os modelos estimados, a aplicação do modelo de fronteira estocástica com efeitos da ineficiência mostrou-se válida, como demonstram o teste de razão de verossimilhança unicaudal (Teste LR) ${ }^{16}$ e o teste sobre o parâmetro $\gamma$, significantemente diferente de zero. A Tabela 3 apresenta alguns outros testes de especificação para o modelo de fronteira estocástica de produção. Os testes de 1 a 3 são do tipo razão de verossimilhança e o teste 4 do tipo Wald. O primeiro teste refere-se à adequação da forma funcional da função de produção. Como mencionado anteriormente, a hipótese nula de uma função Cobb-Douglas é rejeitada em favor da alternativa Translog. $\mathrm{O}$ segundo testa a presença de progresso tecnológico no tempo. Como os coeficientes associados à variável tempo são significantes conjuntamente, rejeitamos a hipótese nula de ausência de progresso tecnológico. $\mathrm{O}$ terceiro testa a significância conjunta dos parâmetros usados na modelagem do componente ineficiência técnica e rejeita a hipótese de que os parâmetros são simultaneamente iguais a zero. A fim de verificar se existe heterogeneidade não-observada nas ineficiências das firmas, estimamos um modelo de efeitos fixos por máxima verossimilhança assumindo que a distribuição dos efeitos das ineficiências é one-sided. Implementamos esse estimador com a inclusão de variáveis indicadoras das empresas como explicativas em $\mu_{\mathrm{i}}$. Entretanto, os testes LR tanto para a função de produção (teste 4 da Tabela 3) quanto para a função de custo mostram que esses efeitos não são significantes. Por fim, a quinta hipótese testada é de que a fronteira estocástica de produção estimada apresenta retornos constantes de escala. No caso da Translog isso representa a imposição de cinco hipóteses simultâneas, as quais são rejeitadas ao nível de 5\%.

Passaremos, agora, à análise dos resultados das funções de produção. Note-se, em primeiro lugar, que as variáveis do modelo utilizado estão centradas em torno da média geométrica da amostra. Esse procedimento torna os coeficientes estimados mais robustos, pelo fato de a função translog ser uma aproximação de segunda ordem de qualquer função de produção arbitrária, em torno da média da amostra. Além disso, ele permite obter as elasticidades da produção em relação aos fatores de produção e a taxa de progresso técnico, avaliadas na média, diretamente das estimativas dos $\beta_{i}$ 's e $\beta_{T}$. Examinando-se a Tabela 2, observa-se que no modelo com retornos variáveis, em geral, os coeficientes de primeira ordem e a maioria dos coeficientes de segunda ordem estimados são significantes e apresentam os sinais esperados.

$16 \mathrm{O}$ teste LR unicaudal testa se a introdução do modelo de ineficiência é justificável estatisticamente, ou seja, se o ajustamento do modelo é melhor do que quando todos os parâmetros do modelo de ineficiência são iguais a zero. Note-se que esse teste apresenta uma distribuição qui-quadrado mista, pois envolve uma hipótese de desigualdade, dado que $\gamma$ é restrito a estar entre 0 e 1 . Os valores críticos para esse teste encontram-se na Tabela 1 de Kodde e Palm (1986). 
Observe-se, ainda que, nesse modelo, a elasticidade de escala, aproximada aqui pela soma das elasticidades-produto, é superior à unidade, indicando assim a presença de economias crescentes de escala, uma vez que a soma dos coeficientes estimados para a mão-de-obra, o capital e o (negativo do) percentual de perdas (proxy para a energia comprada) é maior que 1 . Os coeficientes estimados para o percentual de perdas estão de acordo com as expectativas para o modelo, e indicam que quanto maiores as perdas, menor será o volume de energia suprida pelas distribuidoras. Note-se que as perdas correspondem à diferença entre a energia distribuída e a energia comprada, que constitui o maior aporte de insumos, na distribuição; portanto, essa variável pode ser vista como (o negativo de) um insumo. Os coeficientes $\beta_{t}$, positivos e significantes, indicam a ocorrência de um substancial progresso tecnológico no período analisado. A taxa de progresso técnico anual excede $5 \%$ nas duas especificações, mostrando claramente que uma parte significante do aumento da produtividade na distribuição de energia elétrica é proveniente de deslocamentos na fronteira de produção. Voltaremos a discutir esse ponto quando da análise da produtividade total dos fatores. Os coeficientes associados à variável posse de eletrodomésticos (eletro), incluída para levar em conta o potencial do mercado, não são significantes. Por fim, conforme esperado, a maior dispersão dos consumidores reduz a produção; o valor estimado para o parâmetro da densidade de consumidores é positivo e significante em ambos os modelos. 
TABELA 2 - FRONTEIR A DE PRODUÇÃO COM EFEITOS DE INEFICIÊNCIA

\begin{tabular}{|c|c|c|c|c|}
\hline \multicolumn{5}{|c|}{ Variável Dependente: Volume de Energia Suprida $(Q)$} \\
\hline & \multicolumn{2}{|c|}{ Retornos Variáveis (RVE) } & \multicolumn{2}{|c|}{ Retornos Constantes (RCE) } \\
\hline & Coeficiente & Erro padrão & Coeficiente & Erro padrão \\
\hline$\beta_{0}$ & 0.0499 & 0.0358 & 0.0637 & 0.0452 \\
\hline$\beta_{K}$ & $0.4593^{* *}$ & 0.0447 & 0.5045 & - \\
\hline$\beta_{L}$ & $0.4731^{* *}$ & 0.0542 & $0.4990^{* *}$ & 0.0536 \\
\hline$\beta_{P}$ & $-0.1607^{* *}$ & 0.0644 & -0.0035 & 0.0346 \\
\hline$\beta_{K K}$ & $0.4010^{* *}$ & 0.0529 & 0.2673 & - \\
\hline$\beta_{L L}$ & $0.5051^{* *}$ & 0.0858 & $0.3666^{* *}$ & 0.0905 \\
\hline$\beta_{P P}$ & $0.4579^{* *}$ & 0.1542 & 0.0197 & 0.0175 \\
\hline$\beta_{K L}$ & $-0.9140^{* *}$ & 0.1323 & -0.3071 & - \\
\hline$\beta_{K P}$ & $0.3330^{* *}$ & 0.1170 & 0.0398 & - \\
\hline$\beta_{L P}$ & $-0.5706^{* *}$ & 0.1596 & -0.0595 & 0.0727 \\
\hline$\beta_{K t}$ & $-0.1402^{* *}$ & 0.0285 & -0.1126 & - \\
\hline$\beta_{L t}$ & $0.1623^{* *}$ & 0.0358 & $0.1235^{* *}$ & 0.0341 \\
\hline$\beta_{P t}$ & -0.0437 & 0.0305 & -0.0109 & 0.0120 \\
\hline$\beta_{t}$ & $0.0564^{* *}$ & 0.0113 & $0.0539^{* *}$ & 0.0102 \\
\hline$\beta_{t t}$ & 0.0023 & 0.0048 & 0.0033 & 0.0048 \\
\hline$\alpha \_$eletro & -0.0927 & 0.0793 & 0.1683 & 0.1288 \\
\hline$\alpha_{-}$denscon & $0.0937^{* *}$ & 0.0141 & $0.0602^{* *}$ & 0.0145 \\
\hline \multicolumn{5}{|c|}{ Modelo de Ineficiência Variável Dependente (u) } \\
\hline & \multicolumn{2}{|c|}{ Retornos Variáveis (RVE) } & \multicolumn{2}{|c|}{ Retornos Constantes (RCE) } \\
\hline & Coeficiente & Erro padrão & Coeficiente & Erro padrão \\
\hline$\delta_{0}$ & 0.0577 & 0.0985 & $0.1949^{*}$ & 0.1099 \\
\hline$\delta_{-}$mista & $0.3861^{* *}$ & 0.1589 & 0.3490 & 0.2752 \\
\hline$\delta_{-}$share & $-2.7414^{*}$ & 1.4791 & $-4.0621^{\star}$ & 2.4551 \\
\hline$\delta_{-}$privatização & $-0.3767^{* *}$ & 0.1097 & $-0.5132^{\star *}$ & 0.1522 \\
\hline$\delta_{-}$dec & $-0.0619^{* *}$ & 0.0145 & $-0.0299^{\star *}$ & 0.0116 \\
\hline$\delta_{-} f e c$ & $0.0437^{* *}$ & 0.0089 & $0.0283^{* *}$ & 0.0083 \\
\hline$\delta_{-}$nordeste & $0.1375^{*}$ & 0.0800 & -0.4326 & 0.5404 \\
\hline$\delta_{-}$sul & -0.0588 & 0.1618 & -0.1924 & 0.2400 \\
\hline$\delta_{-}$centro-oeste & $-0.3575^{\star *}$ & 0.0989 & $-0.7926^{\star \star}$ & 0.2405 \\
\hline$\sigma^{2}$ & $0.0390^{* *}$ & 0.0092 & $0.0477^{* *}$ & 0.0159 \\
\hline$\gamma$ & $0.3768^{* *}$ & 0.1177 & $0.3959^{*}$ & 0.2026 \\
\hline Log Verossimilhança & \multicolumn{2}{|c|}{47.4022} & \multicolumn{2}{|c|}{40.7889} \\
\hline Eficiência Média & \multicolumn{2}{|c|}{0.8638} & \multicolumn{2}{|c|}{0.8790} \\
\hline Número de empresas & \multicolumn{2}{|c|}{22} & \multicolumn{2}{|c|}{22} \\
\hline Número de períodos & \multicolumn{2}{|c|}{9} & \multicolumn{2}{|c|}{9} \\
\hline Número de iterações & \multirow{2}{*}{\multicolumn{2}{|c|}{$\begin{array}{r}33 \\
73.2290\end{array}$}} & \multicolumn{2}{|c|}{31} \\
\hline Teste LR para erro $u$ & & & \multicolumn{2}{|c|}{75.6369} \\
\hline
\end{tabular}

Obs.: Estimativas obtidas por meio do programa computacional Frontier Versão 4.1. $\mathrm{O} * *$ indica que os parâmetros são estatisticamente significantes a $5 \% \mathrm{e}^{*}$ indica que os parâmetros são estatisticamente significantes a $10 \%$. 


\section{TABELA 3 - TESTES DE ESPECIFICAÇÃO PARA FRONTEIRA ESTOCÁSTICA PRODUÇÃO (RVE)}

\begin{tabular}{|c|c|c|c|c|c|}
\hline Teste & Hipótese Nula $\left(\mathrm{H}_{0}\right)$ & $\begin{array}{l}\text { Log-Verossi_ } \\
\text { milhança }\end{array}$ & $\begin{array}{c}\text { Estatística } \\
\mathrm{LR}\left(\chi^{2}\right)\end{array}$ & g.l. & Resultado \\
\hline 1 & $\begin{array}{l}\beta_{K K}=\beta_{L L}=\beta_{P P}=\beta_{K L}=\beta_{K P}=\beta_{L P}= \\
=\beta_{K t}=\beta_{L t}=\beta_{P t}=\beta_{t t}=0\end{array}$ & 23.1142 & 48.58 & 10 & Rejeita-se $\mathrm{H}_{0}$ \\
\hline 2 & $\beta_{K t}=\beta_{L t}=\beta_{P t}=\beta_{t}=\beta_{t t}=0$ & -2.3332 & 99.47 & 5 & Rejeita-se $\mathrm{H}_{0}$ \\
\hline 3 & $\delta_{1}=\delta_{2}=\ldots=\delta_{8}=0$ & 12.6346 & 69.53 & 8 & Rejeita-se $\mathrm{H}_{0}$ \\
\hline 4 & Efeitos fixos em $\mu_{i}=0$ & 51.7649 & 8.72 & 21 & $\begin{array}{l}\text { Não se rejeita } \\
\mathrm{H}_{0}\end{array}$ \\
\hline Teste & Hipótese Nula $\left(\mathrm{H}_{0}\right)$ & & $\begin{array}{l}\text { Estatística } \\
\text { Wald }\left(\chi^{2}\right)\end{array}$ & g.l. & Resultado \\
\hline 5 & $\begin{array}{l}\beta_{K}+\beta_{L}+\beta_{P}=1 \\
\beta_{K K}+\beta_{K L}+\beta_{K P}=0 \\
\beta_{K L}+\beta_{L L}+\beta_{L P}=0 \\
\beta_{K P}+\beta_{L P}+\beta_{P P}=0 \\
\beta_{K t}+\beta_{L t}+\beta_{P t}=0\end{array}$ & & 79.14 & 5 & Rejeita-se $\mathrm{H}_{0}$ \\
\hline
\end{tabular}

Analisaremos, agora, o modelo das ineficiências. Em relação às características das firmas, esse modelo mostra que as empresas mistas - que atuam também na geração e na transmissão de eletricidade - tendem a ser mais ineficientes que aquelas que se concentram unicamente na distribuição. Haveria assim, ganhos de eficiência associados à especialização. Esse resultado, porém, não se mantém no modelo com retornos constantes de escala. Ademais, empresas que detêm maior parcela de mercado (share) são mais eficientes, resultado que é consistente com a presença de retornos de escala crescentes, encontrada no modelo RVE. A privatização apresenta efeito redutor sobre as ineficiências das firmas. O coeficiente atrelado a essa variável é significante e negativo.

As variáveis DEC (duração de interrupção de energia por consumidor) e FEC (índice de frequência de interrupção por consumidor) apresentam sinais opostos. O coeficiente positivo, associado ao efeito do número de interrupçôes no sistema, captado no modelo pela variável FEC, sinaliza, como esperado, que essas interrupções contribuem para aumentar a ineficiência. A variável DEC, porém, aparece com sinal negativo, contrariando as expectativas de que a maior duração das interrupções levaria a uma ineficiência maior. Note-se, contudo, que o fato de a variável DEC incluir, 
além das interrupções não programadas, aquelas destinadas à manutenção da rede, pode estar explicando o sinal deste coeficiente. Isto porque é razoável supor que interrupções programadas, que contribuem para a eficiência do sistema, em geral, têm uma duração superior às não programadas; elas estariam, pois, predominando sobre as interrupções mais freqüentes explicando, assim, o sinal negativo associado a variável DEC. Por fim, quanto às dummies regionais, somente a região Centro-Oeste é, inequivocamente, mais eficiente que o Sudeste (região de referência), enquanto a região Nordeste é menos eficiente em relação ao Sudeste na especificação RVE. Note-se que a região Norte não foi considerada porque nenhuma das distribuidoras analisadas situa-se nessa região.

TABELA 4 - ÍNDICES DE EFICIÊNCIA TÉCNICA ESTIMADOS PARA AS DISTRIBUIDORAS DE ENERGIA ELÉTRICA NO BRASIL

\begin{tabular}{lrccccccccc}
\hline EMPRESA & $\begin{array}{c}\text { Número de } \\
\text { Funcionários } \\
\text { em 2001 }\end{array}$ & 1993 & 1994 & 1995 & 1996 & 1997 & 1998 & 1999 & 2000 & 2001 \\
& 2872 & 0.9734 & 0.9671 & 0.9734 & 0.9688 & 0.9748 & 0.9848 & 0.9827 & 0.9841 & 0.9821 \\
\hline COELBA & 978 & 0.9766 & 0.9744 & 0.9739 & 0.9823 & 0.9823 & 0.9817 & 0.9814 & 0.9797 & 0.9792 \\
ENERSUL & 1646 & 0.9369 & 0.9114 & 0.9183 & 0.8800 & 0.9144 & 0.9691 & 0.9752 & 0.9780 & 0.9760 \\
COELCE & 787 & - & - & - & - & 0.8056 & 0.9654 & 0.9710 & 0.9769 & 0.9588 \\
AES & 1913 & 0.9624 & 0.9581 & 0.9485 & 0.9345 & 0.9340 & 0.9398 & 0.9246 & 0.9766 & 0.9772 \\
CELPE & 3982 & 0.9796 & 0.9740 & 0.9780 & 0.9739 & 0.9739 & 0.9829 & 0.9803 & 0.9763 & 0.9774 \\
ELETROPAULO & 1716 & 0.7330 & 0.5376 & 0.5928 & 0.5419 & 0.8239 & 0.9374 & 0.9496 & 0.9678 & 0.9672 \\
CEMAT & 1471 & - & - & - & - & - & - & 0.9685 & 0.9664 & - \\
EBE & 2254 & - & - & - & - & - & - & 0.9677 & 0.9656 & - \\
ELEKTRO & 2217 & 0.9666 & 0.9619 & 0.9597 & 0.9562 & 0.9711 & 0.9641 & 0.9618 & 0.9652 & 0.9581 \\
CELG & 1352 & - & - & - & - & 0.8429 & 0.9633 & 0.9570 & 0.9638 & 0.9672 \\
RGE & 2934 & 0.9011 & 0.8405 & 0.8954 & 0.8848 & 0.8917 & 0.9681 & 0.9595 & 0.9625 & 0.9656 \\
CPFL & 1354 & 0.8768 & 0.7671 & 0.7511 & 0.8041 & 0.9736 & 0.9692 & 0.9679 & 0.9610 & 0.9615 \\
CERJ & 4449 & 0.9031 & 0.8504 & 0.9058 & 0.9727 & 0.9689 & 0.9700 & 0.9643 & 0.9603 & 0.9645 \\
LIGHT & 1292 & 0.9554 & 0.9375 & 0.9284 & 0.9384 & 0.9570 & 0.9542 & 0.9580 & 0.9589 & 0.9462 \\
CEB & 1411 & 0.8878 & 0.8146 & 0.9197 & 0.9707 & 0.9571 & 0.9539 & 0.9559 & 0.9483 & 0.9479 \\
ESCELSA & 4265 & 0.9525 & 0.9418 & 0.9445 & 0.9461 & 0.9465 & 0.9554 & 0.9342 & 0.9103 & 0.9138 \\
CELESC & 11288 & 0.9408 & 0.9254 & 0.9486 & 0.9437 & 0.9373 & 0.5896 & 0.8836 & 0.8726 & 0.8935 \\
CEMIG & 5854 & 0.8793 & 0.7584 & 0.7765 & 0.8828 & 0.8072 & 0.7208 & 0.7033 & 0.7368 & 0.7732 \\
COPEL & 399 & 0.8407 & 0.7820 & 0.7056 & 0.6545 & 0.6973 & 0.7167 & 0.7482 & 0.7177 & 0.6266 \\
CPEE & 2445 & 0.7233 & 0.6521 & 0.7446 & 0.6996 & 0.6650 & 0.5857 & 0.5588 & 0.6549 & 0.6353 \\
CEEE & 750 & 0.6293 & 0.5797 & 0.5409 & 0.5148 & 0.4990 & 0.5261 & 0.5679 & 0.5345 & 0.4768 \\
CFLCL & & & & & & & & & &
\end{tabular}


Os índices de eficiências técnicas estão listados na Tabela 4, ordenados para o ano de 2000, ano mais recente que apresenta índices de eficiência para todas as empresas analisadas. Analisando-se essa tabela, nota-se, em primeiro lugar, que esses índices são relativamente elevados: das 22 empresas consideradas, apenas 3 apresentam níveis de eficiência inferiores a 70\%, no final do período (2001). Ademais, para muitas empresas, a eficiência cresce ao longo do período considerado. Note-se, porém, que uma empresa surge como inlier: a CFLCL (Companhia Força e Luz Cataguazes Leopoldina), que aparece como a menos eficiente em 2000, com índice muito inferior àqueles apresentados por suas congêneres. Isto é ainda mais preocupante quando se considera que a eficiência dessa empresa vem caindo, de maneira sistemática, ao longo do tempo.

Vale salientar que o tamanho da empresa, mensurado em termos do número de funcionários, não parece estar inequivocamente associado aos níveis de eficiência. Assim, por um lado, com exceção da AES (AES Sul Distribuidora Gaúcha de Energia S/A), uma empresa mais nova e que figura entre as mais eficientes, as empresas muito pequenas supostamente não atingem a escala mínima exigida de produção e, portanto, são mais ineficientes em todos os modelos estimados. Por outro lado, dentre as cinco empresas mais ineficientes, encontram-se a COPEL e a CEMIG, consideradas empresas de grande porte. De fato, o grupo que desponta como o mais eficiente é o que inclui as empresas de porte médio, que possuem entre 1000 e 2000 empregados, com uma eficiência média de $0,963 \mathrm{em} 2001$. Esse resultado é consistente com o fato de que as mudanças tecnológicas que ocorreram no setor de distribuição de eletricidade, por reduzirem os problemas das indivisibilidades, diminuíram a importância das economias de escala. Esse ponto será retomado na seção 4.1, onde se discutem as fronteiras de custo-eficiência.

No que tange à evolução dos índices de eficiência, o comportamento das empresas é bastante diverso. Em empresas como a AES e a CEMAT, por exemplo, esses índices cresceram mais de 3\% ao ano, no período 1993/2001. Porém, para a maioria das unidades consideradas, o crescimento da eficiência é bastante limitado, ou mesmo negativo. Esse resultado torna-se mais claro se analisarmos a evolução da produtividade, usando o índice de Produtividade Total dos Fatores de Malmquist (PTF) e seus componentes: (a) o índice de eficiência técnica (ME), que expressa o efeito catching-up, indicando o movimento relativo da firma observada, em direção à fronteira e (b) o índice de mudanças tecnológicas (MT). Conforme anteriormente explicitado, o índice PTF não mensura adequadamente as variações de produtividade em modelos com retornos variáveis. Por essa razão, o cômputo desse indicador baseia-se no modelo com retornos constantes de escala (RCE), apresentado na Tabela 
2. A Tabela 5 mostra a evolução do índice de Malmquist e de seus componentes para o período 1993/2001. Valores desses índices superiores à unidade indicam crescimento de produtividade enquanto valores inferiores a 1 indicam redução da produtividade.

\section{TABELA 5 - ÍNDICES CUMULATIVOS PARA VARIAÇÕES NA EFICIÊNCIA, VARIAÇÕES TECNOLÓGICAS E VARIAÇÓES NA PRODUTIVIDADE - TOTAL DOS FATORES - EMPRESAS PÚBLICAS E PRIVADAS - 1993/2001}

\begin{tabular}{|c|c|c|c|c|c|c|c|c|c|}
\hline \multirow{3}{*}{ Período } & \multicolumn{9}{|c|}{ Índices de Malmquist } \\
\hline & \multirow[b]{2}{*}{ ME } & \multirow{2}{*}{$\begin{array}{l}\text { Total } \\
\text { MT }\end{array}$} & \multirow[b]{2}{*}{ PTF } & \multicolumn{3}{|c|}{ Empresas Públicas } & \multicolumn{3}{|c|}{ Empresas Privadas } \\
\hline & & & & ME & MT & PTF & ME & MT & PTF \\
\hline 1993 & 1.000 & 1.000 & 1.000 & 1.000 & 1.000 & 1.000 & 1.000 & 1.000 & 1.000 \\
\hline $1993 / 94$ & 0.937 & 1.096 & 1.028 & 0.937 & 1.096 & 1.028 & 1.000 & 1.000 & 1.000 \\
\hline $1994 / 95$ & 0.955 & 1.200 & 1.146 & 0.955 & 1.200 & 1.146 & 1.000 & 1.000 & 1.000 \\
\hline $1995 / 96$ & 0.954 & 1.316 & 1.255 & 0.945 & 1.316 & 1.244 & 1.046 & 1.056 & 1.104 \\
\hline $1996 / 97$ & 0.981 & 1.409 & 1.382 & 0.972 & 1.421 & 1.381 & 1.092 & 1.121 & 1.224 \\
\hline $1997 / 98$ & 0.980 & 1.464 & 1.434 & 0.907 & 1.496 & 1.357 & 1.153 & 1.141 & 1.315 \\
\hline $1998 / 99$ & 0.999 & 1.506 & 1.504 & 0.950 & 1.576 & 1.497 & 1.153 & 1.142 & 1.316 \\
\hline $1999 / 00$ & 1.005 & 1.534 & 1.541 & 0.957 & 1.639 & 1.569 & 1.159 & 1.133 & 1.312 \\
\hline $2000 / 01$ & 0.993 & 1.543 & 1.532 & 0.931 & 1.689 & 1.572 & 1.157 & 1.108 & 1.282 \\
\hline
\end{tabular}

O crescimento da produtividade total dos fatores (PTF) para o conjunto das empresas é bastante expressivo no período examinado. Entre 1993 e 2001, esse índice eleva-se em mais de $50 \%$. Note-se, porém, que esse aumento da produtividade decorre, sobretudo, de deslocamentos da fronteira tecnológica, mensurados pelo índice MT. Os níveis de eficiência técnica na distribuição de eletricidade de fato se reduzem entre 1993/2001. ${ }^{17}$ Porém, esses resultados agregados mascaram padrões de comportamento bem distintos. Para ilustrar essas diferenças, dentre os diferentes cortes possíveis, escolhemos distinguir empresas públicas e privadas. ${ }^{18}$ Vê-se, então, que nas empresas privadas, ao contrário de suas congêneres públicas, o crescimento da PTF se dá, principalmente, mediante incremento dos patamares de eficiência. Para as empresas públicas, a produtividade avança sobretudo graças aos deslocamentos da fronteira de produção. Observe-se, ainda, que tais deslocamentos são consistentes

17 Os índices de Malmquist, calculados por empresas, podem ser obtidos com as autoras.

18 Como algumas empresas passaram de públicas a privadas durante o período analisado, uma mesma empresa pode ser considerada pública por alguns períodos e depois de ser privatizada passa a ser considerada privada, para fins de cálculo dos índices de Malmquist por tipo de empresa. 
com a introdução de novas tecnologias e novas formas de gerenciamento, no mercado da distribuição de energia elétrica.

\subsection{Funções de Custo-Eficiência}

O modelo de fronteira estocástica de custo-eficiência estimado tem a seguinte especificação:

$$
\begin{aligned}
\ln C_{i t}= & \beta_{0}+\beta_{1} \ln \text { sal }_{i t}+\beta_{2} \ln \text { custo_energ }_{i t}+\beta_{3} \ln \text { vol_energ }_{i t}+\beta_{11}\left(\ln \text { sal }_{i t}\right)^{2}+ \\
& \beta_{22}\left(\ln \text { custo_energ }{ }_{i t}\right)^{2}+\beta_{33}\left(\ln \text { vol_energ }_{i t}\right)^{2}+\beta_{12} \ln \left(\text { sal }_{i t}\right) \ln \left(\text { custo_energ }_{i t}\right)+ \\
& \beta_{13} \ln \left(\text { sal }_{i t}\right) \ln \left(\text { vol_energ }_{i t}\right)+\beta_{23} \ln \left(\text { custo_energ }_{i t}\right) \ln \left(\text { vol_energ }_{i t}\right)+\beta_{1 t} \ln \left(\text { sal }_{i t}\right) . t+ \\
& \beta_{2 t} \ln \left(\text { custo_energ }_{i t}\right) . t+\beta_{3 t} \ln \left(\text { vol_energ }_{i t}\right) . t+\beta_{t} \cdot t+\beta_{t t} \cdot t^{2}+v_{i t}-u_{i t}
\end{aligned}
$$

$\mathrm{e}$

$\mu_{i t}=\delta_{0}+\delta_{1}$ mista $_{i t}+\delta_{2}$ share $_{i t}+\delta_{3}$ privat $_{i t}+\delta_{4}$ denscon

onde $i$ indica a observação da $i$-ésima firma na amostra; $t$ indica o $t$-ésimo período; $C_{i t}$ é o custo operacional médio; $s_{a l} l_{1 i t}$ é o salário médio; custo_energ ${ }_{i t}$ é o custo da energia comprada; vol_energ ${ }_{i t}$ é o volume de energia suprida $(\mathrm{MWH})$; denscon ${ }_{i t}$ é a densidade de consumidores e os $v_{i t}$ são assumidos variáveis i.i.d. com distribuição $N\left(0, \sigma_{v}^{2}\right)$ independentes dos $u_{i t}$ 's. Os $u_{i t}$ 's são as ineficiências técnicas não-negativas, distribuídas independentemente, tal que $u_{i t}$ é obtido pelo truncamento em zero da distribuição $N\left(\mu_{i t}, \sigma_{u}^{2}\right)$, onde a média é definida como uma função explícita de um vetor de variáveis específicas da firma, tal como especificado, onde as variáveis foram definidas na seção 3. Note-se, por fim, que a localização regional da empresa não afeta os custos; em estimações não reportadas, nenhum dos coeficientes associados às dummies regionais foi significante. Por essa razão, optamos por excluir essas variáveis no modelo de custo. De fato, as estimações da fronteira de produção já antecipavam esse resultado visto que, nessas estimações, somente a região Centro-Oeste era, significativamente, mais eficiente que a região de controle (Sudeste). 
TABELA 6 - FRONTEIRA DE CUSTO-EFICIÊNCIA: CUSTO TOTAL

\begin{tabular}{|c|c|c|}
\hline \multicolumn{3}{|c|}{ Variável Dependente: Log Custo Operacional Total $(C T)$} \\
\hline & Coeficiente & Erro Padrão \\
\hline Const1 & $-0.0910^{\star *}$ & -0.0164 \\
\hline Ln (salário) & $0.0886^{* *}$ & 0.0085 \\
\hline Ln (custo_energia) & $0.5032^{* *}$ & 0.0116 \\
\hline Ln (volume_energia) & $0.9765^{* *}$ & 0.0072 \\
\hline Ln (salário) ${ }^{2}$ & -0.0021 & 0.0091 \\
\hline Ln (custo_energia) $)^{2}$ & $0.1183^{* *}$ & 0.0108 \\
\hline Ln (volume_energia) ${ }^{2}$ & $0.0068^{* *}$ & 0.0027 \\
\hline Ln (salário)^Ln (custo_energ) & 0.0026 & 0.0170 \\
\hline Ln (salário)*Ln (volume_energ) & -0.0144 & 0.0103 \\
\hline Ln (custo_energ)'Ln(vol_energ) & 0.0173 & 0.0138 \\
\hline Ln (salário) * tempo & -0.0001 & 0.0029 \\
\hline Ln (custo_energia)*tempo & $-0.0145^{* *}$ & 0.0033 \\
\hline Ln (volume_energia)*tempo & 0.0004 & 0.0013 \\
\hline Tempo & $-0.0572^{* *}$ & 0.0017 \\
\hline Tempo* Tempo & $0.0020^{* *}$ & 0.0006 \\
\hline \multicolumn{3}{|c|}{ Modelo de Ineficiência } \\
\hline \multicolumn{3}{|c|}{ Variável Dependente: Ineficiência (u) } \\
\hline & Coeficiente & Erro Padrão \\
\hline Const2 & $0.0636^{* *}$ & 0.0184 \\
\hline Mista & -0.0017 & 0.0224 \\
\hline Share & 0.0226 & 0.1597 \\
\hline Privatização & $-0.0678^{* *}$ & 0.0258 \\
\hline Densidade consumidores & $-0.0098^{* *}$ & 0.0038 \\
\hline$\sigma^{2}$ & $0.0015^{* *}$ & 0.0003 \\
\hline$\gamma$ & $0.5421^{* *}$ & 0.1841 \\
\hline Log Verossimilhança & \multicolumn{2}{|c|}{335.1872} \\
\hline Eficiência Média & \multicolumn{2}{|c|}{1.0538} \\
\hline Número de empresas & \multicolumn{2}{|c|}{22} \\
\hline Número de períodos & \multicolumn{2}{|c|}{9} \\
\hline Número de iterações & \multicolumn{2}{|c|}{41} \\
\hline Teste LR para erro $u$ & \multicolumn{2}{|c|}{33.9157} \\
\hline
\end{tabular}

Obs.: Estimativas obtidas por meio do programa computacional Frontier Versão 4.1. O ** indica que os parâmetros são estatisticamente significantes a $5 \% \mathrm{e}^{*}$ indica que os parâmetros são estatisticamente significantes a $10 \%$.

As Tabelas 6 a 8 apresentam os resultados das estimações para o modelo (2). A restrição teórica de homogeneidade linear nos preços dos fatores foi imposta normalizando-se a variável dependente, o salário médio e o custo da energia, pelo custo dos 
outros insumos. Note-se que aqui, também, as variáveis do modelo utilizado estão centradas em torno da média geométrica da amostra.

Vale observar, em primeiro lugar, que a aplicação do modelo de fronteira estocástica para o custo total é adequada, como demonstram o teste de razão de verossimilhança generalizado unicaudal (Teste LR $)^{19}$ e o teste sobre o parâmetro $\gamma$ significantemente diferente de zero. A Tabela 7 apresenta alguns outros testes de especificação para o modelo da fronteira de custo-eficiência. O primeiro teste refere-se à adequação da forma funcional da função de custo. A exemplo do que ocorreu com a produção, rejeita-se a especificação Cobb-Douglas, em favor da função Translog. Testamos, ainda, a existência de progresso tecnológico neutro, ao longo do tempo. Como os coeficientes associados à variável tempo são significantes conjuntamente, rejeitamos a hipótese nula de ausência de progresso tecnológico. Ademais, testamos a significância conjunta dos parâmetros usados na modelagem do componente ineficiência técnica; aqui, rejeita-se, também, a hipótese de que os parâmetros são simultaneamente iguais a zero.

TABELA 7 - TESTES DE ESPECIFICAÇÃO PARA FRONTEIRA DE CUSTOEFICIENCIA

\begin{tabular}{|c|c|c|c|c|c|}
\hline Teste & Hipótese Nula $\left(\mathrm{H}_{0}\right)$ & $\begin{array}{l}\text { Log-Verossi_ } \\
\text { milhança }\end{array}$ & $\begin{array}{c}\text { Estatística } \\
\operatorname{LR}\left(\chi^{2}\right)\end{array}$ & g.l. & Resultado \\
\hline 1 & $\begin{array}{l}\beta_{11}=\beta_{22}=\beta_{33}=\beta_{12}=\beta_{13}=\beta_{23}= \\
=\beta_{1 t}=\beta_{2 t}=\beta_{3 t}=\beta_{t t}=0\end{array}$ & 282.24 & 105.89 & 10 & Rejeita-se $\mathrm{H}_{0}$ \\
\hline 2 & $\beta_{1 t}=\beta_{2 t}=\beta_{3 t}=\beta_{t}=\beta_{t t}=0$ & 112.63 & 445.11 & 5 & Rejeita-se $\mathrm{H}_{0}$ \\
\hline 3 & $\delta_{1}=\delta_{2}=\delta_{3}=\delta_{4}=0$ & 319.10 & 32.17 & 4 & Rejeita-se $\mathrm{H}_{0}$ \\
\hline 4 & Efeitos fixos em $\mu_{i}=0$ & 351.30 & 32.24 & 21 & $\begin{array}{l}\text { Não se } \\
\text { rejeita } \mathrm{H}_{0}\end{array}$ \\
\hline Teste & Hipótese Nula $\left(\mathrm{H}_{0}\right)$ & & $\begin{array}{l}\text { Estatística } \\
\text { Wald }\left(\chi^{2}\right)\end{array}$ & g.l. & Resultado \\
\hline 5 & $\begin{array}{l}\beta_{3}=1 \\
\beta_{33}=0 \\
\beta_{3 t}=0\end{array}$ & & 24.13 & 3 & Rejeita-se $\mathrm{H}_{0}$ \\
\hline
\end{tabular}

Procedemos, então, com um teste LR para a presença de heterogeneidade nãoobservada nas ineficiências das firmas - modelo com efeitos fixos - o qual mostra

19 Note-se que esse teste apresenta uma distribuição qui-quadrada mista, pois envolve uma hipótese com desigualdade, dado que $\gamma$ é restrito a estar entre 0 e 1 . Os valores críticos para esse teste encontram-se na Tabela 1 de Kodde e Palm (1986). 
que esses efeitos não são significantes. Por fim, testamos para a presença de retornos constantes de escala através da imposição de três restrições simultâneas e um teste do tipo Wald, o qual rejeita tal hipótese.

Examinando-se os resultados expostos na Tabela 6, observa-se que a maioria dos parâmetros estimados é estatisticamente significante e tem o sinal esperado. Em particular, a função de custo total é crescente na produção e nos preços fatoriais. Notese que a baixa elasticidade do custo total em relação ao salário $(0.0886)$ evidencia o caráter capital-intensivo do setor. Os custos respondem principalmente a mudanças no preço da energia e no custo dos outros insumos (essa variável foi utilizada para impor a condição de homogeneidade linear; o seu coeficiente linear, calculado a partir da restrição e dos outros coeficientes estimados, é de 0.4082). A elasticidade do custo em relação ao produto é inferior à unidade. Portanto, um acréscimo de $1 \%$ na produção eleva os custos em aproximadamente $0.98 \%$. Esse resultado é consistente com a presença de economias crescentes de escala, que podem ser aproximadas pela expressão $^{20}$ :

$$
E S=1 /(\partial \ln C / \partial \ln y)
$$

Aqui, ES é igual a 1.024. Porém, o baixo valor desse parâmetro sugere que as indivisibilidades na distribuição de eletricidade são, relativamente, limitadas. Esses resultados são, pois, compatíveis com aqueles obtidos por meio da estimação da fronteira de produção. Finalmente, no que diz respeito ao progresso técnico, observa-se que no período observado, o coeficiente negativo atrelado à variável tempo (- 0.0572) indica que a presença de progresso técnico na distribuição de eletricidade contribuiu para reduzir os custos ao longo do período analisado.

Examinando-se os resultados para o modelo de ineficiências, vê-se que, contrariamente à produção, os custos não parecem ser afetados pelo poder de mercado da empresa, mensurado aqui pela variável "share". Além disso, o impacto positivo da especialização sobre a redução de custos não mais se verifica. $\mathrm{O}$ coeficiente atrelado à variável "mista" não é significante. Conforme esperado, o coeficiente da variável densidade de consumidores - que indica a extensão e a configuração geográfica do sistema de distribuição, com o qual a firma se confronta - é negativo e significante. Maiores concentrações de consumidores permitem que as firmas distribuam mais energia por unidade de insumo. Note-se por fim que, a exemplo da produção, o processo de privatização leva inequivocamente à redução da ineficiência. Em todas as especificações testadas o coeficiente associado à dummy privatização é negativo

20 Ver a esse respeito, Caves e Christensen (1988). 
e significante. Esse ponto é relevante porque sugere que a quebra do monopólio estatal, nesse setor, gerou ganhos de eficiência.

Os níveis de custo-eficiência estimados estão listados na Tabela 8, ordenados pelo ano de 2000. Cabe, aqui, salientar que quanto mais altos esses índices, menor a eficiência das firmas. Assim, por exemplo, a CFLCL, cujo índice de eficiência é 1,883 em 2001, surge como a empresa mais ineficiente, já que seus custos operacionais são quase $9 \%$ superiores ao custo mínimo exigido, caso essa distribuidora estivesse na fronteira de eficiência. Nesse sentido, as empresas mais eficientes em termos de custo são AES (1,0183 em 2001), a ELETROPAULO (1,0092 em 2001) e a CERJ (1,0115 em 2001). Dentre as empresas mais ineficientes, além da CFLCL, já citada, incluem-se a CELESC (1,0825 em 2001), a COPEL(1,0690, em 2001) e a CELG (1,0749 em 2001)

TABELA 8 - ÍNDICES DE EFICIÊNCIA DE CUSTOS ESTIMADOS PARA AS DISTRIBUIDORAS DE ENERGIA ELÉTRICA

\begin{tabular}{|c|c|c|c|c|c|c|c|c|c|c|}
\hline EMPRESA & $\begin{array}{l}\text { Número de } \\
\text { Funcionários } \\
\text { em } 2001\end{array}$ & 1993 & 1994 & 1995 & 1996 & 1997 & 1998 & 1999 & 2000 & 2001 \\
\hline AES & 787 & - & - & - & - & 1.0294 & 1.0120 & 1.0079 & 1.0109 & 1.0183 \\
\hline ELETROPAULO & 3982 & 1.0210 & 1.0540 & 1.0191 & 1.0190 & 1.0270 & 1.0183 & 1.0131 & 1.0115 & 1.0092 \\
\hline CERJ & 1354 & 1.0703 & 1.1117 & 1.0574 & 1.0519 & 1.0164 & 1.0245 & 1.0147 & 1.0119 & 1.0115 \\
\hline CPFL & 2934 & 1.0619 & 1.1072 & 1.0538 & 1.0503 & 1.0573 & 1.0452 & 1.0224 & 1.0148 & 1.0151 \\
\hline RGE & 1352 & - & - & - & - & 1.0159 & 1.0172 & 1.0158 & 1.0157 & 1.0392 \\
\hline LIGHT & 4449 & 1.0360 & 1.0730 & 1.0299 & 1.0098 & 1.0126 & 1.0248 & 1.0194 & 1.0170 & 1.0145 \\
\hline ELEKTRO & 2254 & - & - & - & - & - & - & 1.0200 & 1.0199 & - \\
\hline CELPE & 1913 & 1.0757 & 1.1124 & 1.0710 & 1.0683 & 1.0780 & 1.0940 & 1.0792 & 1.0201 & 1.0213 \\
\hline ESCELSA & 1411 & 1.0419 & 1.0778 & 1.0235 & 1.0112 & 1.0136 & 1.0256 & 1.0190 & 1.0240 & 1.0181 \\
\hline EBE & 1471 & - & - & - & - & - & - & 1.0290 & 1.0250 & - \\
\hline ENERSUL & 978 & 1.0722 & 1.1069 & 1.0713 & 1.0341 & 1.0334 & 1.0402 & 1.0258 & 1.0251 & 1.0266 \\
\hline COELCE & 1646 & 1.0680 & 1.1022 & 1.0679 & 1.0641 & 1.0637 & 1.0358 & 1.0260 & 1.0261 & 1.0188 \\
\hline COELBA & 2872 & 1.0572 & 1.0921 & 1.0576 & 1.0511 & 1.0504 & 1.0373 & 1.0351 & 1.0263 & 1.0233 \\
\hline CEEE & 2445 & 1.0373 & 1.0604 & 1.0488 & 1.0487 & 1.0234 & 1.0548 & 1.0559 & 1.0282 & 1.0608 \\
\hline CEMAT & 1716 & 1.1146 & 1.1524 & 1.1133 & 1.1012 & 1.0936 & 1.0742 & 1.0328 & 1.0321 & 1.0515 \\
\hline CPEE & 399 & 1.0572 & 1.0991 & 1.0519 & 1.0522 & 1.0640 & 1.0868 & 1.0594 & 1.0551 & 1.0487 \\
\hline CEMIG & 11288 & 1.0729 & 1.1028 & 1.0791 & 1.0806 & 1.0890 & 1.1359 & 1.0612 & 1.0598 & 1.0684 \\
\hline CEB & 1292 & 1.0585 & 1.0910 & 1.0521 & 1.0513 & 1.0595 & 1.0866 & 1.0595 & 1.0629 & 1.0432 \\
\hline CELG & 2217 & 1.0554 & 1.0910 & 1.0510 & 1.0475 & 1.0463 & 1.0666 & 1.0795 & 1.0640 & 1.0749 \\
\hline COPEL & 5854 & 1.0495 & 1.0763 & 1.0708 & 1.0738 & 1.0874 & 1.1066 & 1.0822 & 1.0654 & 1.0690 \\
\hline CFLCL & 750 & 1.0482 & 1.0882 & 1.0513 & 1.0547 & 1.0702 & 1.0962 & 1.0697 & 1.0795 & 1.0883 \\
\hline CELESC & 4265 & 1.0719 & 1.1081 & 1.0694 & 1.0675 & 1.0783 & 1.1003 & 1.1062 & 1.0966 & 1.0825 \\
\hline
\end{tabular}


Nossos resultados mostram que, para a maioria das empresas, a eficiência técnica aumenta durante o período analisado. Isso se reflete na redução dos índices estimados de custo-eficiência. De fato, apenas seis empresas - CEEE, CELESC CELG, CFLCL, COPEL e RGE - afastam-se da fronteira de custo-eficiência nesse mesmo período. Note-se que, em média, o desperdício de recursos entre 1993 e 1999 oscila em torno de $6 \%$ para o conjunto das empresas; a partir desse ano, ele diminui para menos de $4 \%$, para $2000 / 2001$.

Por fim, no tocante ao impacto do tamanho da empresa sobre a eficiência em termos de custo, vale o anteriormente mencionado na Seção 4: o tamanho não parece influenciar os índices de eficiência. De fato, a AES, empresa pequena, obtém o melhor desempenho, enquanto empresas de grande porte como a CELESC e a COPEL figuram entre as empresas mais ineficientes. Ademais, os índices de custo-eficiência não se modificaram muito no período analisado. Muitas empresas, inclusive, pioraram o seu desempenho, como é o caso da CEEE, CELG, CELESC e CFLCL.

\section{CONCLUSÃO}

Esse trabalho preenche uma lacuna importante no que diz respeito à avaliação do desempenho das distribuidoras de energia elétrica no Brasil. Trata-se de um estudo que utiliza um instrumental, que se apoia solidamente na teoria econômica e é suficientemente flexível para ser operacionalizado e usado como forma de avaliação sistemática e permanente pela agência reguladora, podendo, futuramente, servir para orientar a fixação de marcos regulatórios.

Os resultados obtidos a partir das funções de produção apontam para a presença de retornos de escala no setor; porém, essas economias de escala são relativamente pequenas. Esse resultado é consistente com as recentes mudanças no padrão tecnológico no setor de distribuição de eletricidade, que permite uma maior divisibilidade do processo produtivo. Note-se, ainda, que o processo de privatização parece ter induzido ganhos de eficiência para as empresas analisadas. Em praticamente todas as formas testadas, a desestatização do setor contribuiu, de forma significante, para aumentar a eficiência das empresas consideradas.

Por fim, a extensão da metodologia utilizada, para permitir a existência de coeficientes variáveis, pode acrescentar informações importantes no que diz respeito às especificidades das empresas analisadas e será objeto de futuros trabalhos. 


\section{REFERENCIAS}

AIGNER, D. J.; CHU; S. F. On estimating the industry production function. The American Economic Review, v. 58, n. 4, p. 826-839, 1968.

AIGNER, D.J .; LOVELL, C. A. K.; SCHMIDT, P. Formulation and estimation of stochastic frontier production function models. Journal of Econometrics. NorthHolland, v. 6, p. 21-37, 1977.

ARCOVERDE, F. D. Mensuração e modelagem das eficiências das distribuidoras do setor energético brasileiro usando fronteiras estocásticas. 2005. Dissertação (Mestrado). Departamento de Economia - UNB. Brasília.

BANKER, R. D. Maximum likelihood, consistency and data envelopment analysis: a statistical foundation. Management Science, v. 39, n. 10, p. 1265-1273, 1993.

BATTESE, G. E.; COELLI, T. J. A model for technical inefficiency effects in a stochastic frontier production function for panel data. Empirical Economics, v. 20, p. 325-332, 1995.

. Frontier production functions, technical efficiency and panel data: with application to Paddy farmers in India. Journal of Productivity Analysis, v. 3, p. 153-169, 1992.

. Prediction of firm-level technical efficiencies with a generalised frontier production function and panel data. Journal of Econometrics, North-Holland, v. 38, p. 387-399, 1988.

BATTESE, G. E.; COELLI, T. J.; COLBY, T. C. Estimation of frontier production functions and the efficiencies of Indian farms using panel data from ICRISAT's Village Level Studies. Journal of Quantitative Economics, v. 5, p. 327-348, 1989.

BATTESE, G. E.; CORRA, G. S. Estimation of a production frontier model: with application to the pastoral zone of Eastern Australia. Australian Journal of Agricultural Economics, v. 21, p. 169-179, 1977.

BAUER, P.W. Recent developments in the econometric estimation of frontiers. Journal of Econometrics, North-Holland, v. 46, p. 39-56, 1990.

CAVES, D. W.; CHRISTENSEN, L. R. The importance of economies of scale, capacity utilization and density in explaining inter-industry differences in productivity growth. The Logistics and Transportation Review, 2, p. 3-32, 1988.

COELLI, T. J. A guide to FRONTIER version 4.1: a computer program for stochastic frontier production and cost function estimation. CEPA Working Paper 96/07. Department of Econometrics, University of New England, Armidale, Australia, 1999.

COELLI, T. J.; RAO, D. S. Prasada; BATTESE, G. E. An Introdution to Efficiency and Productivity Analysis. $3^{\text {a }}$ ed. London: Kluwer Academic Publishers, 1998. 
DANILIN, V. I.; MATEROV, I. S.; ROSEFIELD, S.; LOVELL, C. A. K. Measuring enterprise efficiency in the Soviet Union: A stochastic frontier analysis. Econometrica, New Series, v. 52, n. 206, p. 225-233, 1985.

FARREL, M. J. The measurement of productive efficiency. Journal of the Royal Estastistical Society. Series A (General), v. 120, n.3, p. 253-290, 1957.

GREENE, W. H. Econometric Analysis. 5 ${ }^{\mathrm{a}}$ ed. New Jersey: Prentice Hall, 2002 (Capítulo 16, p.429: Estimation Frameworks in Econometrics; Capítulo 17, p.501-505: Maximum Likelihood Estimation)

. Frontier production functions. In: PESARAN, M.; SCHMIDT, P. Handbook of Applied Econometrics. London: Blackwell Publishers, vol. II: Microeconomics, 1997, p. 141-163.

. The econometric approach to efficiency analysis. In: FRIED, H.O., LOVELL, C.A.K.; SCHMIDT, S.S. (Ed.). The measurement of productive efficiency. New York: Oxford University Press, 1993, p. 68-119.

.A gamma-distributed stochastic frontier model. Journal of Econometrics. North-Holland, v. 46, p. 141-163, 1990.

. On the estimation of a flexible frontier production model. Journal of Econometrics. North-Holland, v. 13, p. 101-115, 1980.

HUGHES, M. D. A stochastic frontier cost function for residential child care provision. Journal of Applied Econometrics, v. 3, p. 203-214, 1988.

JONDROW, J.; LOVELL, C. A. K.; MATEROV, I. S.; SCHMIDT, P. On the estimation of technical inefficiency in the stochastic frontier production function model. Journal of Econometrics. North-Holland, v. 19, p. 233-238, 1982.

KODDE, D.A.; PALM, F. C. Wald criteria for jointly testing equality and inequality restrictions. Econometrica, v. 54, n. 5, p. 1243-1248, 1986.

KUMBHAKAR, S. C.; GHOSH S.; MCGUCKIN, J. T. A generalized production frontier approach for estimating determinants of inefficiency in U.S. Dairy Farms. Journal of Business and Economic Statistics, v. 9, p. 279-286, 1991.

KUMBHAKAR, S. C.; TSIONOS, E. G. Estimation of stochastic frontier production function with input oriented technical efficiency. Journal of Econometrics, $\mathrm{v}$. 133, p. 71-96, 2006.

LIMA, R. L. P. Avaliação do uso de métodos não paramétricos no processo regulatório do setor elétrico no Brasil. 2003. Dissertação (Mestrado), Departamento de Economia da Universidade de Brasília-UNB.

MEEUSEN, W.; VAN DEN BROECK, J. Efficiency estimation from Cobb-Douglas production functions with composed error. International Economic Review, v. 18, n. 2, p. 435-444, 1977.

PINDYCK, R. S.; RUBINFELD, D. L. Microeconomia. 2a ed. São Paulo: Makron Books, 1994. 
PITT, M. M.; LEE, L. F. Measurement and sources of technical inefficiency in the Indonesian weaving industry. Journal of Development Economics, v. 9, p. 43-64, 1981.

REIFSCHNEIDER, D.; STEVENSON, R. Systematic departures from the frontier: a framework for the analysis of firm inefficiency. International Economic Review, v. 32, n. 3, p. 715-723, 1991.

SCHMIDT, P.; LOVELL, C. A. K. Estimating technical and allocative inefficiency relative to stochastic production and cost frontiers. Journal of Econometrics. North-Holland, v. 9, p. 343-366, 1979.

STEVENSON, R. E. Likelihood functions for generalized stochastic frontier estimation. Journal of Econometrics. North-Holland, v. 13, p. 57-66, 1980.

WANG, H.; SCHMIDT, P. One-step and two-step estimation of the efffects of exogenous variables on technical efficiency levels. Journal of Productive Analysis, v. 18, p. 129-144, 2002.

\section{OUTRAS FONTES}

ANEEL - Agência Nacional de Energia Elétrica. Disponível em: < http://www. aneel.gov.br>.

BNDES - Banco Nacional de Desenvolvimento Econômico e Social. Disponível em: $<$ http://www.bndes.gov.br>.

CEPA - Centre for Efficiency and Productivity Analysis. Disponível em: < http:// www.uq.edu.au/economics/cepa/>.

IBGE - Instituto Brasileiro de Geografia e Estatística. Disponível em: < http://www. ibge.gov.br>. 
ANEXO 1 - DISTRIBUIDORAS DE ENERGIA ELÉTRICA

\begin{tabular}{|c|c|c|}
\hline \multirow[t]{2}{*}{ EMPRESA } & \multirow[t]{2}{*}{ RAZÃO SOCIAL } & \\
\hline & & ATUAÇÃO \\
\hline AES-SUL & AES Sul Distribuidora Gaúcha de Energia S/A & RS \\
\hline CEB & Companhia Energética de Brasília & DF \\
\hline CEEE & Companhia Estadual de Energia Elétrica & RS \\
\hline CELESC & Centrais Elétricas de Santa Catarina & SC/PR \\
\hline CELG & Companhia Energética de Goiás & GO \\
\hline CELPE & Companhia Energética de Pernambuco & PE/PB \\
\hline CEMAT & Centrais Elétricas Matogrossenses S/A & MT \\
\hline CEMIG & Companhia Energética de Minas Gerais & MG/RJ \\
\hline CERJ & Companhia de Eletricidade do Estado do Rio de Janeiro & MG/RJ \\
\hline CESP & Companhia Energética de São Paulo & SP \\
\hline CFLCL & Companhia Força e Luz Cataguazes Leopoldina & MG/RJ \\
\hline CHESF & Companhia Hidroelétrica São Patrício & GO \\
\hline COELBA & Companhia de Eletricidade do Estado da Bahia & BA \\
\hline COELCE & Companhia Energética do Ceará & CE \\
\hline COPEL & Companhia Paranaense de Energia & $\mathrm{PR} / \mathrm{SC}$ \\
\hline CPEE & Companhia Paulista de Energia Elétrica & SP \\
\hline CPFL & Companhia Paulista de Força e Luz & SP \\
\hline EBE & Empresa Bandeirante de Energia & SP \\
\hline ELEKTRO & ELEKTRO - Eletricidade e Serviços S/A & MS/SP \\
\hline ELETRONORTE & Centrais Elétricas do Norte do Brasil S/A & AM/RR \\
\hline ELETROPAULO & Eletropaulo Metropolitana Eletricidade de São Paulo S/A & SP \\
\hline ENERSUL & Empresa Energética do Mato Grosso do Sul S/A & MS \\
\hline ESCELSA & Espírito Santo Centrais Elétricas S/A & ES \\
\hline LIGHT & Light Serviços de Eletricidade S/A & RJ \\
\hline RGE & Rio Grande Energia S/A & RS \\
\hline
\end{tabular}

